\title{
“A Review Article onEffect of Cutting Parameter on Drilling Operation for Perpendicularity"
}

\author{
Asst.Prof.J.Patel ${ }^{1}$,A.Intwala ${ }^{2}$, D.Patel ${ }^{3}$, D.Gandhi ${ }^{4},{ }$ N.Patel ${ }^{5}$, M.Patel $^{6}$ \\ ${ }^{1-6}$ Department of Mechanical Engineering, Sigma institute of Engineering, Gujarat, India.
}

\begin{abstract}
The effect of drilling parameter such as spindle speed, feed rate and coolant ratio for obtaining optimum perpendicularity for materials EN8,EN24 \&EN31 as a work piece materials using cobalt alloy steel drill with point angle $135^{\circ}$ and helix angle $30^{\circ}$. This study shows that how significant the drilling parameter are for obtaining optimum perpendicularity. Analysis of variance (ANOVA) was carried out for perpendicularity and their contribution rates determined optimum cutting conditions for least perpendicularity defect obtained by using design of experiments (DOE) methodology for achieving optimization using Minitab 16 software.
\end{abstract}

Keyword: Machining process(Drilling), Perpendicularity, EN8, EN24, EN31.

\section{Introduction}

Drilling is most efficient and economical method of cutting a hole in a solid metal. Drilling can be described as a process where a multi-point tool is used to remove unwanted materials to produce a desired hole. It broadly covers those methods used for producing cylindrical holes in the work piece. Hole making had long been recognized as the most prominent machining process, requiring specialized techniques to achieve optimum cutting condition. The Drilling machines are highly used in an industry for metal removal operation. It is therefore, essential to optimize quality and productivity simultaneously[1-4].It has been reported that drilling accounts for nearly $40 \%$ of all the metal removal operation in the aerospace and automobile industries. The making of an aerospace part has evolved frommetallic components to composite material. Thecomposite material is an ideal replacement material forthe structures of the aerospace due to the light weight characteristics. Drilling operation have a considerable economic importance.In machining, drilling is essentially required to joint different structure but carbon steel material (EN8,EN24\&EN31) drilling posses many problem encountered include Geometric Dimensioning and Tolerances(GD\&T)requirements, perpendicularity and other major problems.

In order to minimize these machining problems, there is need to develop scientific methods to select cutting conditions for damage free drilling operation.Thus, the choice of optimized cutting parameter is very important for controlling required perpendicularity.An engineering drawing of a production part conveys information from the designerto the manufacturing and inspection. It must contain all information necessary for thepart to be correctly manufactured and inspected. The systemof geometric tolerancingoffers a precise interpretation of drawing requirements.

Geometric dimensioning and tolerancing is a system of symbols developed and used to defined part shapes, feature form, orientation, runout, profile and location. Once tolerances are assigned, it should leave no doubt as to what is desirable and also acceptable to satisfy design intent. It is a system based on function and interrelationship of mating features while keeping in mind manufacturing and inspection capabilities.Economy and repeatability are also key consideration given when applying geometric controls and will be further elaborated on throughout the body of this text. [33]

Geometric tolerance characteristics are categorized as Form, Orientation, Profile, Runout and Location. Orientation contains Perpendicularity, Parallelism \& Angularity. They require the use of datums.Perpendicularity is a member of the orientation family(fig.1)it can be used tocontrol the orientation of surface, axes and centerplanes. If used on features of size, itis often used as a refinement of, or to augment a positional control. It is also often usedto orient secondary datum features of size to primary plane datums. Perpendicularity isa characteristics of orientation (altitude) applied to a feature or feature of size whereinthat considered feature surface, line element, median plane or axis is being controlled(to within a specified tolerance) $90^{\circ}$ to a datum plane or datum axis. 


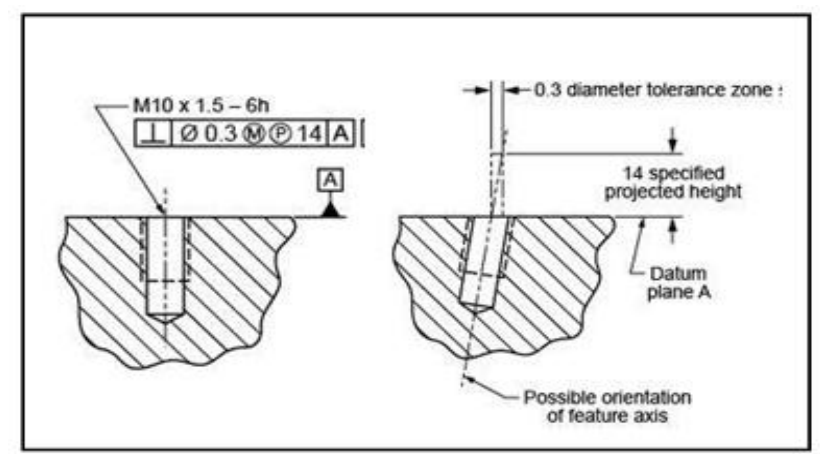

Figure: 1 Measurement of Perpendicularity [33]

The example given in (fig.1) depicts a typical application of perpendicularity. Forthe component to function well as part of the assembly, it is required thatperpendicularity of the bore $\varnothing 18$ withreference to datum $\mathrm{A}$ is required as specified atMMC. Such, explicit depictions would produce functional assembly and products.

Also, A large number of experimental works have to be carried out when the number of process parameters increases. To solve this problem, the Taguchi method uses a special design of orthogonal arrays to study the entire parameter space with only a small number of experiments $[5,35]$.

\section{Literature Review}

P.M. George Et Al [6] investigated to achieve the optimum perpendicularity on the carbon steel materials EN8 and EN31 which were made by extrusion process fig.2 shows the schematic diagram of experimental setup based on which experiments were carried out.

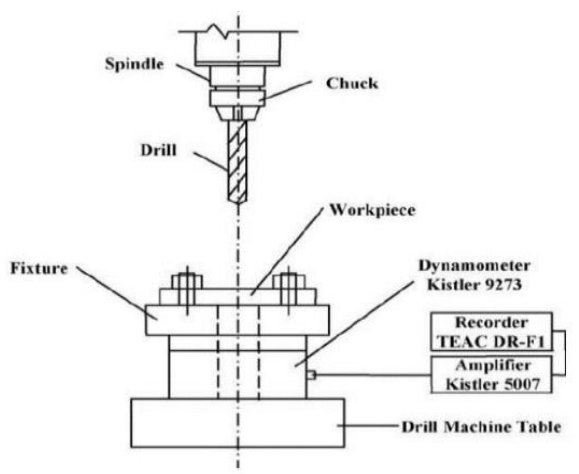

Figure: 2 Schematic Diagram Setup [6] [32]

Full Factorial Design:Full factorial design is used for simultaneous study of several factor effects on the process. By varying levels of factors simultaneously we can find optimal solution. Responses are measured at all combinations of the experimental factor levels. The combination of the factor levels represent the conditions at which responses will be measured. Each experiment condition is a run of an experiment. The response measurement is an observation. The entire set run is a design. It is used to find out the variables which are the most influence on the response and their interactions between two or more factors on responses

\section{Main effect plots analysis for Perpendicularity ofEN8 [6]:}

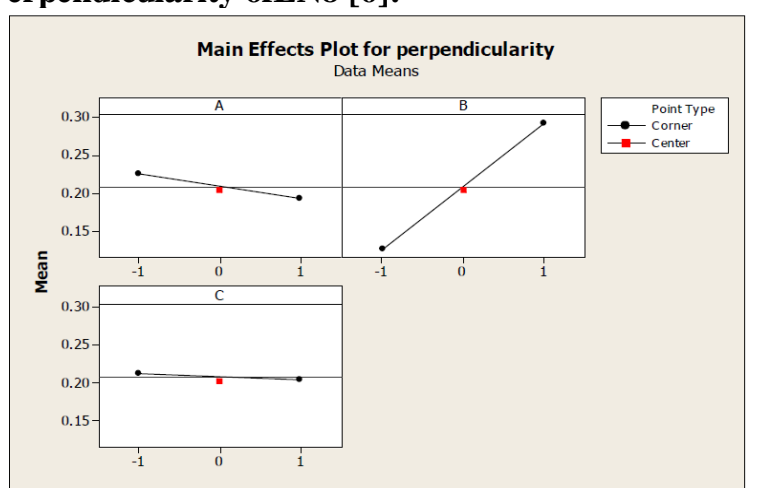

Figure: 3 Main Effects Plots for Perpendicularity of EN8 
Fig. 3 shows the main effects plot for perpendicularity. According to this main effect plot, the optimal conditions for minimum perpendicularity in EN8 are at spindle speed $500 \mathrm{rpm}$, feed $0.1 \mathrm{~mm} / \mathrm{rev}$ and coolant ratio $20 \%$ oil.

\section{Main effect plots analysis for Perpendicularity ofEN31 [6]:}

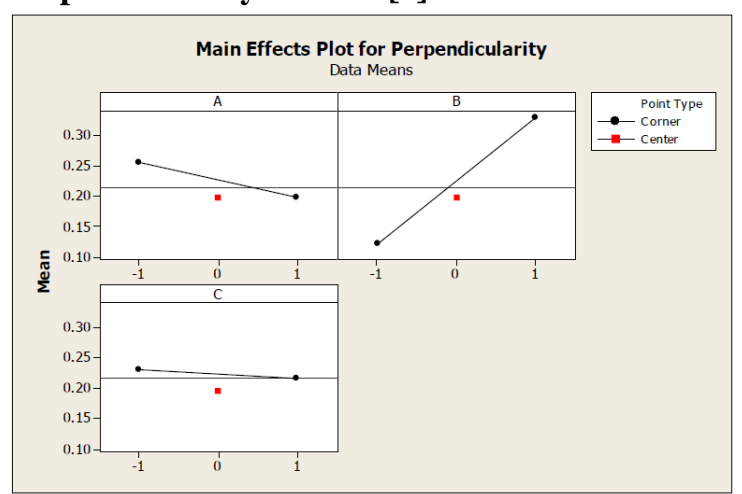

Figure: 4 Main Effects Plots for Perpendicularity OfEN31

Fig.4 shows the main effects plot for perpendicularity of EN31. According to this main effect plot, the optimal conditions for minimum perpendicularity are at cutting speed $400 \mathrm{rpm}$, feed $0.15 \mathrm{~mm} / \mathrm{rev}$ and coolant ratio $20 \%$ oil. From the above experiment result, he finally concluded that irrespective of material (EN8, EN31), spindle speed, feed rate plays an important role in affecting the perpendicularity in drilling operation by using DOE concept.Evren Kabakli et al [7]analyzed that various response parameters (i.e. surface roughness, perpendicularity and cylindricity) are affected by different controlled factors (i.e. hole diameter, hole depth, feed rate and peripheralcutting speed) due to which the deflection of tool increases and concluded that hole depth is insignificant on drilling and feed rate is insignificant mostly on cylindricity. Biren Desai et al [8] investigated that for finding optimum cutting conditions for defect free drilling, spindle speed is most effective parameter for measuring circularity and feed is most effective parameters hole size through drilling operation.Mihir T. Patel et al [9] tried to investigated that by studying several research paper for surface roughness the most significant parameters are speed, feed and nose radius \& least significant is DOC, feed \& speed and least significant parameter is nose radius.Azudin Mamat et al [10] made some several conclusions based on main objective of study and result from experiment: (a) thevalue of surface roughness are mostly influenced by spindle speed \& feed rate. Also, metal removal rate (MRR) decreases with decrease in tool diameter, spindle speed and feed rate.(b)For accuracy ofholedrills; as drill diameter, feed rate \& spindle speed increases the dimensional accuracy of drilled hole will decrease.Vinod Kumar Vankanti et al [11] the conclusions drawn from their work i.e. ANOVA reveals that feed rate and speed are the most significant factor on the thrust force, torque and surface finish. Also, speed and chisel angle width are most influencing factors on circularity error of the hole. B Kumaragurubaran et al [12] after conducting the experiments of turning parameters on EN-9 steel rods and optimum parameters of surface roughness \& metal removal rate are given below: (a)Spindle speed is dominating parameter of turning process.(b)Feed rate is most significant parameter of metal removal rate of turning operation.A M Badadhe et al [13]studied and concluded that the use of taguchi parameter design technique was considered successful as efficient method to optimize machining parameters in a boring operation which will tend to reduce machining time \& productivity. S R Das et al [14] tried to conclude that: (a) the taguchi parameter design is an effective way of determining the optimal cutting parameters for achieving low tool wear and low workpiece surface temperature. (b) The significant parameters for workpiece surface temperature were cutting speed and depth of cut with contribution of $41.17 \%$ and $34.45 \%$ respectively. (c) Also, the relationship between cutting parameters(cutting speed, depth of cut, feed) and the performance measures (tool wear and work piece surface temperature) are expressed by multiple regression equation which is used in estimating the expressed values of performance level for any parameter levels.

Table: 1Cutting Parameters and Levels [14]

\begin{tabular}{|c|c|c|c|c|}
\hline \multirow{2}{*}{ Parameters } & \multirow{2}{*}{ Unit } & \multicolumn{3}{|c|}{ Levels } \\
\cline { 3 - 5 } & & 1 & 2 & 3 \\
\hline Depth of Cut (D) & $\mathrm{mm}$ & 0.5 & 0.75 & 1.0 \\
\hline Feed (F) & $\mathrm{mm} / \mathrm{rev}$ & 0.15 & 0.2 & 0.25 \\
\hline Cutting speed(V) & $\mathrm{m} / \mathrm{min}$ & 150 & 200 & 250 \\
\hline
\end{tabular}




\section{Main Effect Plots:}

The data was further analyzed to study the interact on amount cutting parameters $(\mathrm{V}, \mathrm{D}, \mathrm{F})$ and the main effect plots on tool wear and workpiece surface temperature were analyzed with the help of software package MINITAB15 and shown in Figures 5 and 6 respectively. The main effect plots are used to determine the optimal design conditions to obtain the low tool wear and low surface temperature. Figure 5 shows the main effect plot for tool wear(TW). The results show that with the increase in cutting speed there is a continuous increase in tool wear. On the other hand, as the feed increases the tool wear decreases.
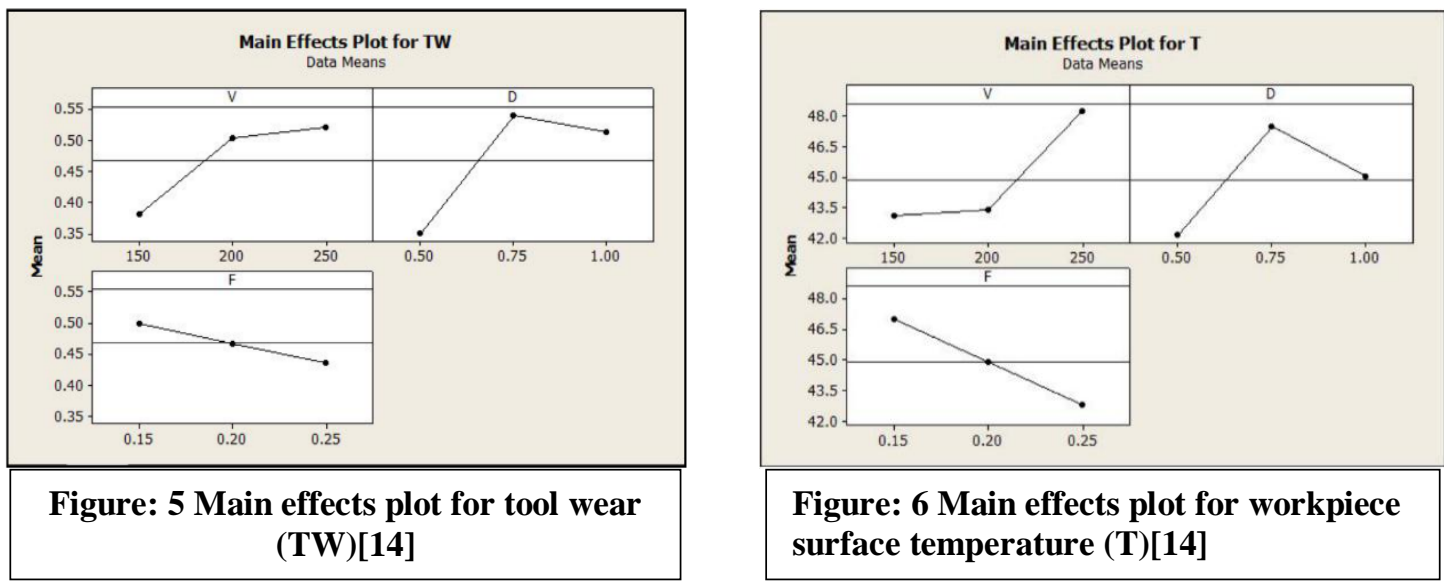

Based on analysis using Figure. 5 low value of tool wear was obtained at cutting speed of $150 \mathrm{~m} / \mathrm{min}$ (level-1), DOC of $0.5 \mathrm{~mm}$ (level-1) and feed of $0.25 \mathrm{~mm} / \mathrm{rev}$ (level-3). The main effects plot for workpiece surface temperature Figure 6 shows that same levels of cutting parameters (V: $150 \mathrm{~m} / \mathrm{min}, \mathrm{D}: 0.5 \mathrm{~mm}$ and F: $0.25 \mathrm{~mm} / \mathrm{rev}$ ) produce lower workpiece surface temperature, T. Thus, the lower surface temperature gives less tool wear on the cutting tools.

The following equations are the final regression models in terms of coded parameters for:

Tool wear (TW):

$\mathrm{TW}=0.069+0.0014 \mathrm{~V}+0.327 \mathrm{D}-0.633 \mathrm{~F}(\mathrm{R}=0.85)$

Workpiece surface temperature $(\mathrm{T})$ :

$\mathrm{T}=38.7+0.0517 \mathrm{~V}+5.73 \mathrm{D}-42.0 \mathrm{~F}(\mathrm{R}=0.80)^{[9]}$

A Y Mustafa Et Al [15] in this study, aluminium workpieces were produced by machine-turning, which is an important form of metal fabrication. The dimensional precision and surface quality of the workpiece were analyzed and the potential effects of variables such as workpiece size, workpiece diameter, cutting depth and feed rate on these dependent variables were investigated.A Taguchi method was used in the study, in order to help obtain more reliable results and therefore save time and cost in a real production environment, by obtaining optimal results. This method informed the experimental design; fewer experiments were required and more efficient outcomes were achieved; thus, time and cost were reduced by avoiding unnecessary experiments. The study also investigated vibration, which is considered to be important in generation of surface roughness and dimensional errors in metal cutting. The study determined appropriate cutting parameters to minimize vibration. The Taguchi optimization method was successfully applied in the study. Machining parameters such as cutting forces, surface roughness, cylindricity and vibration were minimized; process performance was enhanced and product quality was improved.Hamzeh Shahrajabian et al [16] based on the experimental results, the following conclusions were drawn that surface roughness increases, when feed increases and decreases, when cutting speed increases; with an higher cutting speed and lower feed, it is possible to obtain better surface finish. Analysis of variance (ANOVA) for thrust force, delamination and roughness showed that feed rate is most significant factor.A Fata et al [17] (a) The tests indicated that it was possible to relate changes in tool loading, under identical cut and feed conditions, directly with tool wear conditions. (b) It was noted that worn vee profile tools tended to produce a greater increase in the vertical force component than theaxial component, whereas knife tools tended to show a more pronounced increase in the axial component. (c)To take into account variations in depth of cut, feed and cutting speed it was thought that wear condition should be related to changes in the specific cutting force in the direction of the plane of maximum cutting force.(d)It was found that for the tools under test a general increase in the specific cutting force in the plane of maximum force was $3 \times$ sharp values, which corresponded to a flank wear state of approximately $0.6 \mathrm{~mm}$ on high speed steel cutting tools.Pratap singh et al [18] the effects of different process parameters (coolant condition, cutting 
speed, feed, depth of cut, nose radius) on response characteristics (material removal rate, surface roughness), were studied on EN36 material in CNC turning.

In order to validate the results obtained two confirmation experiments were conducted for each of the response characteristics (MRR, SR) at optimal levels of the process variables. The average values of the characteristics were obtained and compared with the predicted values. The results are given in Table 2 . The values of MRR and Surface roughness obtained through confirmation experiments are within the $95 \%$ of CICE of respective response characteristic. It is to be pointed out that these optimal values are within the specified range of process variables.

\begin{tabular}{|c|c|c|c|c|c|}
\hline \multicolumn{6}{|c|}{ TABLE: 2 L18 Orthogonal Array [18] } \\
\hline \multirow{3}{*}{$\begin{array}{l}\text { Trial } \\
\text { No. } \\
\text { Noi. }\end{array}$} & \multicolumn{5}{|c|}{ L18(21X34) } \\
\hline & 1 & 2 & 3 & 4 & 5 \\
\hline & A & $\mathrm{B}$ & $\mathrm{C}$ & $\mathrm{D}$ & $\mathrm{E}$ \\
\hline 1 & WET & 250 & 0.5 & 1.0 & 0.5 \\
\hline 2 & WET & 250 & 0.75 & 1.5 & 0.8 \\
\hline 3 & WET & 250 & 0.62 & 0.62 & 1.4 \\
\hline 4 & WET & 350 & 0.5 & 0.5 & 0.5 \\
\hline 5 & WET & 350 & 0.75 & 0.75 & 0.8 \\
\hline 6 & WET & 350 & 0.62 & 0.62 & 1.4 \\
\hline 7 & WET & 500 & 0.5 & 0.5 & 0.5 \\
\hline 8 & WET & 500 & 0.75 & 0.75 & 0.8 \\
\hline 9 & WET & 500 & 0.62 & 0.62 & 1.4 \\
\hline 10 & DRY & 250 & 0.5 & 0.5 & 0.5 \\
\hline 11 & DRY & 250 & 0.75 & 0.75 & 0.8 \\
\hline 12 & DRY & 250 & 0.62 & 0.62 & 1.4 \\
\hline 13 & DRY & 350 & 0.5 & 0.5 & 0.5 \\
\hline 14 & DRY & 350 & 0.75 & 0.75 & 0.8 \\
\hline 15 & DRY & 350 & 0.62 & 0.62 & 1.4 \\
\hline 16 & DRY & 500 & 0.5 & 0.5 & 0.5 \\
\hline 17 & DRY & 500 & 0.75 & 0.75 & 0.8 \\
\hline 18 & DRY & 500 & 0.62 & 0.62 & 1.4 \\
\hline
\end{tabular}

\begin{tabular}{|l|l|l|l|}
\hline \multicolumn{3}{|c|}{ TABLE: 3.1 Experimental Results for } \\
Surface Roughness [18]
\end{tabular}

\begin{tabular}{|l|l|l|l|}
\hline \multicolumn{3}{|c|}{$\begin{array}{l}\text { TABLE: 3.2 Experimental Results for } \\
\text { material removal rate [18] }\end{array}$} \\
\hline \hline $\begin{array}{l}\text { Trial } \\
\text { NO. }\end{array}$ & $\begin{array}{l}\text { Material Removal } \\
\left.\text { Rate(mm }{ }^{3} / \mathrm{min}\right)\end{array}$ & $\begin{array}{l}\text { S/N } \\
\text { Ratio }\end{array}$ \\
\cline { 2 - 3 } & R1 & R2 & \\
\hline 1 & 45532.15 & 45805.89 & 90.730 \\
\hline 2 & 85287.84 & 87642.41 & 97.789 \\
\hline 3 & 42338.64 & 43399.63 & 96.744 \\
\hline 4 & 63668.92 & 65306.12 & 96.495 \\
\hline 5 & 47818.29 & 49049.66 & 96.432 \\
\hline 6 & 98863.07 & 101317.12 & 94.915 \\
\hline 7 & 45532.15 & 46647.23 & 98.810 \\
\hline 8 & 239520.95 & 245398.77 & 104.010 \\
\hline 9 & 198019.80 & 203045.68 & 105.540 \\
\hline 10 & 34149.11 & 34985.42 & 90.850 \\
\hline 11 & 34115.13 & 35056.42 & 91.032 \\
\hline 12 & 98765.43 & 101265.82 & 98.968 \\
\hline 13 & 79586.15 & 81632.65 & 93.188 \\
\hline 14 & 23909.14 & 24524.83 & 90.794 \\
\hline 15 & 59317.84 & 60790.27 & 99.446 \\
\hline 16 & 91064.31 & 93294.46 & 100.766 \\
\hline 17 & 138869.11 & 140227.87 & 101.419 \\
\hline 18 & 141442.71 & 145032.63 & 101.762 \\
\hline
\end{tabular}

\begin{tabular}{|l|l|l|l|l|}
\hline Response & $\begin{array}{l}\text { Optimal Set of } \\
\text { Parameter }\end{array}$ & $\begin{array}{l}\text { Predicted Optimal } \\
\text { Value }\end{array}$ & Predicted Intervals & Actual Value \\
\hline MRR & A1B3C2D1E2 & $\begin{array}{l}183092 \\
\mathrm{~mm}^{3} / \mathrm{min}\end{array}$ & $\begin{array}{l}114756< \\
\mu \mathrm{MRR}<132867\end{array}$ & $\begin{array}{l}184051 \\
\mathrm{~mm}^{3} / \mathrm{min}\end{array}$ \\
\hline SR & A1B3C1D1E1 & $1.9625 \mu \mathrm{m}$ & $0<\mu \mathrm{SR}<1.052$ & $1.4 \mu \mathrm{m}$ \\
\hline
\end{tabular}

TABLE: 4 Predicted Optimal Values, Confidence Intervals and Results Of Confirmation Experiments[18]

Based on the results obtained, the following conclusions can be drawn: (a)Analysis of Variance suggests the depth of cut is the most significant factor for both surface roughness and MRR and Feed is most in significant factor for surface roughness and spindle speed for MRR. (b)The results obtain by this method will be useful to other research for similar type of study and may be eye opening for further research on tool vibration, power consumption, temperature effects (only in dry condition).M N Islam et al [19] researched that canned cycles have profound effect on quality of drilled holes. In general, the spot drilling canned cycles (G81) produced the best results. Also, all three quality characteristics considered diameter error, circularity, and surface roughnessdeteriorate due to the pecking action of the chip breaking canned cycle (G73) and deep hole canned cycle (G83) which should be avoided unless there are requirements compelling their use. Vishal Francis et al [20]the study discusses about the application of Taguchi method and ANOVA to investigate the effect of process parameters on Tool life. From the analysis of the results obtained following conclusion can be drawn. (a) Statistically designed experiments based on Taguchi method are performed using L9 orthogonal array to analysed Tool life. The results obtained from analysis of S/N Ratio and ANOVA were in close agreement. (b) Linear regression equation is developed to predict the values of Tool life, and the predicted values are compared with the measured value.K. Lipin et al [21] observed that (a)The optimum speed for a particular setup is 
affected by many factors, including Composition, hardness \& thermal conductivity $(\mathrm{k})$ of material, Depth of hole,Efficiency of cutting fluid type, condition and stiffness of drilling machines, Stiffness of workpiece, fixture and tooling (shorter is better) Quality of holes desired, Life of tool before regrind or replacement. (b) Feed to be used depending on the following factors, finish required, Power available, Condition of machine and its drive etc.(c) Surface roughness is determined by several factors which include cutting parameters such as cutting speed, feed, depth of cut, Tool geometry, The material of the cutting tool, Machining condition etc.S. Chung[22] modelled one and two dimensional heat transferphenomenon inthe drilling processes. He stated that heat source and temperature distribution can be estimated in thick workpieces.Agapiou and Stephenson ${ }^{[23]}$ developed a method to compute drill temperature and concluded that point angle and helix angle influence the drill temperature. YogendraTyagi et al [24]discussed the feasibility of machining Mild Steel by drilling machine with a HSS Tool. Taguchi method has been used to determine the main effects significant factors and optimum machining condition to the performance of drilling hole in mild steel based on the results presented here in, We can conclude that, the Spindle Speed of drilling machine Tool mainly affects the SR. The Feed Rate largely affects the MRR.C. Manikandan et al [25]observed that, Taguchi's orthogonal array provides a large amount of information in a small amount of experimentation. All the three parameters are predominantly contributing to the response and all have been considered. Optimum machining parameter combination was found through Taguchi technique.N. Keerthi et al [26] studied that work is used to predict the responses in wide range of input data and it can further be extended for other process while cutting different materials. From ANOVA torque is mostly affected by feed ,cutting force is mostly affected by spindle speed, surface roughness is mostly affected by feed,material removal rate is mostly affected by spindle speed and power is mostly affected by spindle speed.

Table 8 -- Summary of The Review Based On The Methodology[1-4,27-31]

\begin{tabular}{|c|c|c|c|}
\hline $\begin{array}{l}\text { SR } \\
\text { NO. }\end{array}$ & Title of Paper & Author & Controllable Parameter \\
\hline 1 & $\begin{array}{l}\text { Application of grey relational analysis for } \\
\text { surface roughness and roundness error in } \\
\text { drilling of Al } 6061 \text { alloy }\end{array}$ & $\begin{array}{l}\text { Reddy Sreenivasalu } \\
\text { Dr.CH.Sreenivasa Rao }\end{array}$ & $\begin{array}{l}\text { Cutting speed, } \\
\text { Feed rate, } \\
\text { Drill diameter, } \\
\text { Point angle, } \\
\text { Cutting fluid mixture ratio }\end{array}$ \\
\hline 2 & $\begin{array}{l}\text { Operational Modeling For Optimizing } \\
\text { Surface roughness In Mild steel Drilling } \\
\text { Using Taguchi Technique }\end{array}$ & $\begin{array}{l}\text { DineshKumar,L.P } \\
\text { Singh,Gagandeep Singh }\end{array}$ & $\begin{array}{l}\text { Cutting speeds, } \\
\text { Feed rate, } \\
\text { Point angle }\end{array}$ \\
\hline 3 & $\begin{array}{l}\text { Parametric Optimization of Drilling } \\
\text { Machining Process using Taguchi Design } \\
\text { and ANOVA Approach }\end{array}$ & $\begin{array}{l}\text { YogendraTyagi, Vedansh } \\
\text { Chaturvedi,Jyoti Vimal }\end{array}$ & $\begin{array}{l}\text { Spindle speeds, } \\
\text { Feed rate, } \\
\text { Depth of Cut }\end{array}$ \\
\hline 4 & $\begin{array}{l}\text { Experimental Investigation of Process } \\
\text { Parameters in drilling operation using } \\
\text { different softwere technique }\end{array}$ & $\begin{array}{l}\text { Anil Jindal, Dr. V. K. } \\
\text { Singla }\end{array}$ & $\begin{array}{l}\text { Spindle speeds } \\
\text { Feed rate } \\
\text { Depth of cut }\end{array}$ \\
\hline 5 & $\begin{array}{l}\text { Multiple Response Optimization in } \\
\text { Drilling Using Taguchi and Gray } \\
\text { Relational Analysis }\end{array}$ & $\begin{array}{l}\text { B. Shivapragash } \\
\text { K. Chandrasekaran, } \\
\text { C.Parthasarathy, } \\
\text { M.Samuel }\end{array}$ & $\begin{array}{l}\text { Spindle speed } \\
\text { Feed rate } \\
\text { Depth of cut }\end{array}$ \\
\hline 6 & $\begin{array}{l}\text { The Optimization of Machining } \\
\text { Parameters Using the Taguchi Method for } \\
\text { Surface Roughness of AISI } 8660 \\
\text { Hardened Alloy Steel }\end{array}$ & Ali RizaMotoreu & $\begin{array}{l}\text { Cutting speed } \\
\text { Feed rate } \\
\text { Depth of cut } \\
\text { Tool nose radius }\end{array}$ \\
\hline 7 & $\begin{array}{l}\text { Application of Taguchi Method for } \\
\text { Surface Rough ness and Roundness Error } \\
\text { in Drilling of AISI316 Stainless Steel }\end{array}$ & $\begin{array}{l}\text { Adem Cicek } \\
\text { Turgey Krvak } \\
\text { GureanSamtas }\end{array}$ & $\begin{array}{l}\text { Cutting speed } \\
\text { Cutting speed } \\
\text { Feed rate }\end{array}$ \\
\hline 8 & $\begin{array}{l}\text { Optimization of } 6061 \mathrm{~T} 6 \text { CNC Boring } \\
\text { Process Using the Taguchi Method and } \\
\text { Grey Relational Analysis by }\end{array}$ & $\begin{array}{l}\text { Show-Shyan Lin } \\
\text { Ming-Tsan Chuang, } \\
\text { Jeong-Lian Wen } \\
\text { Yung Kuang Yang }\end{array}$ & $\begin{array}{l}\text { Feed Rate } \\
\text { Cutting Speed }\end{array}$ \\
\hline 9 & $\begin{array}{l}\text { Experimental Analysis On Surface } \\
\text { Roughness Of CNC End Milling Process } \\
\text { Using Taguchi Design Method }\end{array}$ & Patel K.P & $\begin{array}{l}\text { Tool Speed } \\
\text { Tool Feed } \\
\text { Depth of Cut } \\
\text { Tool Diameter }\end{array}$ \\
\hline
\end{tabular}

\section{Conclusion}

a) By reviewing the above all research paper, we finally come to the conclusion that by using proper optimization method like Taguchi method, Design Of Experiment(DOE) and efficient software like (Mini 
tab 16,Analysis of variance[ANOVA]), we can obtain optimum response parameters such as surface roughness, perpendicularity, cylindricity and circularity.

b) Also, we can find out the most effectiveor significant controlled factor (Feed rate, cutting speed, depth of cut etc.) affecting the various response parameters and the different machining operation like drilling, reaming, boring, turning.

[1]. R. Sreenivasalu, and S. Rao, (), Application of grey relational analysis for surface roughness and roundness error in drilling of $\mathrm{Al}$ 6061 alloy,International Journal of Lean Thinking, Vol. 3, No. 2, 2012, pp. 67-78.

[2]. D. Kumar, L.P. Singh and G. Singh, , Operational Modeling For Optimizing Surface roughness in Mild Steel Drilling Using Taguchi Technique, International Journal of Research inManagement, Vol. 2, No. 3, 2012, pp. 66-77.

[3]. Y. Tyag, V. Chaturvedi, and J. Vimal, Parametric Optimizatio of Drilling Machining Process using Taguchi Design and ANOVA Approach, Journal of Emerging Technology and AdvancedEngineering, Vol. 2, No. 7, 2012, pp. 339-347.

[4]. Jindal and V.K. Singla, , Experimental Investigation of Process Parameters in drilling operation using different software technique, International Journal of Engineering Sciences, Vol. 1, No. 1, 2011, pp. 135-154.

[5]. Lin T.R, - Cutting behavior using variable feed and variable speed when drilling stainless steel with TiNcoated carbide drills,\| International J. Advance Manufacturing Technology., 19: 629-636,2002.

[6]. P. M George, V. J. Patel, B. P. Patel "Experimental Studies on Perpendicularity of Drilling Operation using DOE"International Journal of Advance Engineering and Research Development (IJAERD) Volume 1,Issue 3, April 2014, e-ISSN: 2348 - 4470 , printISSN:2348-6406.

[7]. EvrenKabakli, MelihBayramoðlu, Necdet Geren "Evaluation of the surface roughness and geometric accuracies in a drilling process using the taguchi analysis" ISSN 1580-2949 Original scientific article MTAEC9, 48(1)91(2014).

[8]. Biren Desai, JaypalsinhRana "Machining Characterization Of Cfrp Laminates With Respect To Drilling Operation"- A Review Sendil Et Al., Journal Of Engineering Research And Studies, Jers, Ahmedabad, India, Oct.-Dec., 2012.

[9]. Mihir T. Patel , Vivek A. Deshpande "Optimization of Machining Parameters for Turning Different Alloy Steel Using CNC Review" International Journal of Innovative Research in Science, Engineering and Technology Vol. 3, Issue 2, February 2014ISSN: 2319-8753.

[10]. Azlan Abdul Rahman, Azuddin Mamat "Effect Of Machining Parameters On Hole Quality Of Micro Drilling For Brass" Modern Applied Science, University Of Malaya Research University, May 2009.

[11]. Vinod Kumar Vankanti, Venkateswarlu Ganta, "Optimization of process parameters in drilling of GFRP composite using Taguchi method" J mater. Res. technology. 2014; 3(1):35-41.

[12]. B Kumaragurubaran, P Gopal, T Senthil Kumar, M Prasanna Mugunthan1and N H Mohamed Ibrahim "Optimization of turning parameters of en-9 steel using design of experiments concepts" ISSN 2278 - 0149 www.ijmerr.comVol. 2, No. 3, July 2013.

[13]. A.M.Badadhe, S. Y. Bhave, L. G. Navale, "Optimization Of Cutting Parameters In Boring Operation" Iosr Journal Of Mechanical And Civil Engineering Pune,India, 2005.

[14]. S.R. Das, R.P. Nayak, D. Dhupal "Optimization of cutting parameters on tool wear and workpiece surface temperature in turning of AISI D2 steel".

[15]. Y. Mustafa And T. Ali, "Determination And Optimization Of The Effect Of Cutting Parameters And Workpiece Length On The Geometric Tolerances And Surface Roughness In Turning Operation” International Journal Of The Physical Sciences, March, 2011.

[16]. HamzehShahrajabian, MostafaHadi, Masoud Farahnakian "Experimental Investigation of Machining Parameters on Machinability of Carbon Fiber/Epoxy Composites" International Journal of Engineering and Innovative Technology (IJEIT) Volume 2, Issue 3, September 2012

[17]. Fata, B. Nikuei "The Effect of the Tool Geometry and Cutting Conditions on the Tool Deflection and Cutting Forces" World Academy of Science, Engineering and Technology Vol: 4 2010-09-25.

[18]. KaushalPratap Singh, Girish Dutt Gautam, Rupesh Yadav, Lalit Bisht, Gavendra Norkey "Selection of Optimum Machining Parameters For EN36 Alloy Steel in CNC Turning Using Taguchi Method" International Journal of Scientific \& Engineering Research, Volume 5, Issue 3, March-2014 ISSN 2229-5518.

[19]. M. N. Islam, N. H. Rafi, and P. Charoon "An Investigation into Effect of Canned Cycles on Drilled Hole Quality" Proceedings of the World Congress on Engineering London, U.K, Vol I, July 2009.

[20]. Vishal Francis, Sumit k Singh "Investigating the Effect of Machining Parameters On Tool Life For Turning of En08" Volume: 2 , Issue: 6, June 2013, ISSN No 2277-8179.

[21]. K. Lipin,Dr. P. Govindan “A Review on Multi Objective Optimization of Drilling Parameters Using Taguchi Methods"

[22]. S. Chung, Temperature estimation in drilling processes byusing an observer International Journal of Machine Tool andManufacturing 45 (2005) 1641-1651.

[23]. J. Agapiou, D. Stephenson, Analytical and ExperimentalStudies of Drill Temperature, ASME Transactions Trans. 54 (1994) 116

[24]. Armstrong KB, Barrett RT. Care and repair of advanced composites. Warrendale, Pa., Society of Automotive Engineers.(1998).

[25]. C. Manikandan, B. Rajeswari,"Study of Cutting Parameters on Drilling EN24 Using Taguchi Method", International Journal of Engineering Research \& Technology (IJERT) ISSN: 2278-0181, Vol. 2 Issue 7, July - 2013

[26]. N. Keerthi, Dr.Syed AltafHussian "Modelling and Analysis of Machining Characteristics of En-8 Steel in Drilling Process",International Journal of Engineering Research \& Technology (IJERT) Vol. 2 Issue 11, November - 2013 ISSN: 22780181

[27]. B. Shivapragash, K. Chandrasekharan, C. Parthasarathy and M. Samuel, Multiple Response Optimizations in Drilling Using Taguchi and Grey Relational Analysis, International Journal ofModern Engineering Research, Vol. 3, No. 2, 2013, pp.765-768.

[28]. R. Riza Motorcu, , The Optimization of Machining Parameters Using the Taguchi Method for Surface Roughness of AISI 8660 Hardened Alloy Steel. Journal of Mechanical Engineering, Vol.56, No. 6, 2010, pp. 391-401.

[29]. Cicek, T. Kivak and G. Samtas, Application of Taguchi Method for Surface Roughness and Roundness Error in Drilling of AISI 316 Stainless Steel,Journal of Mechanical Engineering, Vol. 58, No. 3, 2012, pp. 122-129.

[30]. S. Lin, M. Chuang, J. Wen and Y. Yang, , Optimization of 6061T6 CNC Boring Process Using the Taguchi Method and Grey 21 OPTIMIZATION OF DRILLING PARAMETERS Relational Analysis, The Open Industrial and ManufacturingEngineering Journal, Vol. 2, No. 1, 2009, pp.308-313.

[31]. K.P. Patel, Experimental Analysis On Surface Roughness Of CNC End Milling Process Using Taguchi Design Method, International Journal of Engineering Science and Technology, Vol. 4, No. 2, 2012, pp.540-545.

[32]. Jain R.K. "Production Technology" Khanna Publishers, 2009.

DOI: 10.9790/1684-11661118 www.iosrjournals.org 17 | Page 
[33]. James D Meadows “Geometric Dimensioning and Tolerancing” Marcel Dekker.

[34]. [Pritam Singh Gill "Geometric Dimensioning and Tolerancing” S.K. Kataria \&Sons, 2006

[35]. Montgomery Douglas C, - Introdcution to Statistical Quality Control, 5th edtion. United States of America: John Wiley \& Sons, Inc., 2005 . 